KLEINE TEXTE FÜR VORLESUNGEN UND ÜBUNGEN

HERAUSGEGEBEN VON HANS IIETZMANN

152

\title{
EPISTULA APOSTOLORUM
}

NACH DEM ÄTHIOPISCHEN UND KOPTISCHEN TEXTE

\section{HERAUSGEGEBEN}

voN

HUGO DUENSING;

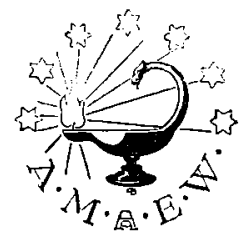

B () N N

A. MARCUS UND E, WEBER'S VERLAG 1925 
A11e Rechte vorbehalten. 